\title{
Beyond Systemic Hypertension: Understanding Cardiac Dysfunction in Obstructive Sleep Apnea
}

\author{
David W. Hudgel \\ Case Western Reserve University, Pulmonary Division, MetroHealth Medical Center, Cleveland, Ohio, USA
}

In this issue of Respiration, Alchanatis et al. [1] report their evaluation of left ventricular (LV) cardiac function in patients with obstructive sleep apnea (OSA) before and after 3 months of nocturnal nasal continuous positive airway pressure (nCPAP) treatment. The authors attempted to look beyond the known effects of systemic hypertension as a cause of LV dysfunction (LVD) in OSA by limiting the investigation to patients without a history of or current systemic hypertension. Even in this group of OSA patients without known hypertension, elevation of diastolic blood pressure was identified during wakefulness and sleep. Consistent with this finding was the presence of diastolic LVD in these patients. Abnormalities nearly completely resolved with nCPAP therapy. This study demonstrates that the identification of factors other than hypertension that may affect LV function, such as apneic activity per se, hypoxemia, hypercapnia, and/or arousals becomes difficult in the human OSA disease model $[2,3]$.

Theoretically, several physiologic events that occur with upper airway closure during sleep might affect LV performance. The recurring nature of these events, 100s of times per night, surely might result in persistent LVD. LV afterload is increased by sympathetic nervous system, hypoxemic and hypercapnic stimulation of peripheral vasoconstriction. The large subatmospheric inspiratory intrathoracic pressure present during an obstructive apnea would be expected to increase preload by increasing

\begin{tabular}{ll}
\hline KARGER & ( 2000 S. Karger AG, Basel \\
0025-7931/00/0674-0360\$17.50/0 \\
$\begin{array}{l}\text { Fax +4161306 1234 } \\
\begin{array}{l}\text { E-Mail karger@karger.ch } \\
\text { www.karger.com }\end{array}\end{array}$ & $\begin{array}{l}\text { Accessible online at: } \\
\text { www.karger.com/journals/res }\end{array}$
\end{tabular}

venous return to the right side of the heart. These large pleural pressure swings would be expected to increase LV afterload by the large LV transmural pressure gradient. In addition to increasing afterload, the high LV transmural pressure gradient also may impair diastolic relaxation and thereby LV filling. With increased right ventricular volume and the presence of hypoxia-induced elevated pulmonary artery pressure, the interventricular septum may be displaced leftward during diastole, which would further impede LV filling. Myocardial contractility may be decreased by hypoxia, hypercapnia, and respiratory acidosis. In addition, the commonly present coronary artery disease, congestive heart failure and obesity in an OSA population would likely potentiate the myocardial dysfunction produced by the apnea-related factors mentioned above. Animal studies have been able to separate the effects of these individual variables to some extent.

The work of Scharf's group $[4,5]$ in a pig model of OSA is applicable to this question. These studies demonstrated that (1) the large pleural pressure swings that occur during OSA did not produce cardiac dysfunction; this was likely due to the lack of a significant change in the mean pleural pressure during the apneas; (2) the increased LV afterload and decreased $\mathrm{CO}$ produced by obstructive apneas in pigs was primarily due to sympathetic nervous system-induced increase in systemic vascular resistance in response to hypoxemia since oxygen administration or pharmacological sympathetic blockade reduced the LVD consider-

Dr. D.W. Hudgel

Pulmonary Division

MetroHealth Medical Center

2500 MetroHealth Drive

Cleveland, OH 44109-1998 (USA) 
ably, and (3) acute coronary artery occlusion and the resultant myocardial ischemia worsened the decrease in CO during OSA. In another study by these investigators [6], adding rapid pacing-induced $\mathrm{CHF}$ to repetetive obstructive apneas resulted in an exaggerated fall in $\mathrm{CO}$ because of a decreased LV preload probably secondary to hypoxia-induced decrease in end-diastolic LV compliance. Thus, these investigations emphasize the importance of hypoxemia and sympathetic nervous system stimulation in causing the cardiac dysfunction in OSA.

From the studies of Bradley's group [7] it is clear that OSA may produce, or more likely potentiate pre-existing
LVD in humans. In patients with OSA, LVD and CHF, nCPAP decreased LV afterload and heart rate, thereby improving LV performance. nCPAP improved respiratory and cardiac performance in acute decompensated $\mathrm{CHF}$ in those with dilated cardiomyopathy by decreasing both LV preload and afterload [8]. Therefore, nCPAP not only resolves OSA and improves sleep pattern, eliminates the hypoxemia and associated enhancement in the sympathetic nervous system activity, it improves LV function, even in patients with primary cardiac disease. Thus, nCPAP is a therapeutic tool that may prove to be as valuable to cardiologists as to pulmonary-sleep physicians.

\section{References}

1 Alchanitis M, Paradellis G, Pini H, Tourkohoriti G, Jordanoglou J: Left ventricular function in patients with obstructive sleep apnoea syndrome before and after treatment with nasal continuous positive airway pressure. Respiration 2000;67:367-371.

2 Somers VK, Dyken ME, Clary MP, Abboud FM: Sympathetic neural mechanisms in obstructive sleep apnea. J Clin Invest 1996;96: 1897-1904.
3 Hedner J, Ejnell H, Sellgren J, Hedner T, Wallin G: Is high and fluctuating muscle sympathetic activity in the sleep apnoea syndrome of pathogenetic importance for the development of hypertension? J Hypertens 1988;6(suppl): 529-531.

4 Chen L, Scharf SM: Comparative hemodynamic effects of periodic obstructive and simulated central apneas in sedated pigs. J Appl Physiol 1997;83:485-494.

5 Chen L, Scharf SM: Systemic and myocardial hemodynamics during periodic obstructive apneas in sedated pigs. J Appl Physiol 1998;84: 1289-1298.
6 Chen L, Shi Q, Scharf SM: Hemodynamic effects of periodic obstructive apneas in sedated pigs with congestive heart failure. J Appl Physiol 2000;88:1051-1060.

7 Tkacova R, Rankin F, Fitzgerald FS, Flores JS, Bradley TD: Effects of continuous positive airway pressure on obstructive sleep apnea and left ventricular afterload in patients with heart failure. Circulation 1998;98:2269-2275.

8 Lenique F, Habis M, Lofaso F, Dubois-Rande JL, Harf A, Brichard L: Ventilatory and hemodynamic effects of continuous positive airway pressure in left heart failure. Am J Respir Crit Care Med 1997;155:500-505. 